\title{
RUMO À "DESCONSTRUÇÃO" \\ DO MANIFESTO PRAGMÁTICO DE RICHARD POSNER: UMA APROXIMAÇÃO METODOLÓGICA VIA J. M. BALKIN ${ }^{1}$
}

Henrique Silva de Oliveira ${ }^{2}$

\section{RESUMO}

O trabalho é uma revisão bibliográfica de três textos representativos da Filosofia do Direito norte-americana, na busca por associações e dissociações neles registradas acerca da metodologia da pesquisa aplicada ao Direito. O método empreendido é o das aproximações sucessivas, com a desconstrução de matriz derridariana. A resenha é utilizada para aproximação com as técnicas propostas discursivas, a fim de produzir asserções comuns aos autores examinados. Conclui-se com a sinalização crítica da relevância dos trabalhos e da corrente jusfilosófica para o estudo da Filosofia do Direito, considerando a vocação dos seus cultores para a solução concreta das questões da vida.

PALAVRAS-CHAVE: metodologia; pesquisa; direito; pragmatismo; desconstrutivismo.

\section{TOWARDS A "DECONSTRUCTION" OF RICHARD POSNER'S PRAGMATIC MANIFESTO: A METHODOLOGICAL APPROACH THROUGH J. M. BALKIN}

\begin{abstract}
The work is a bibliographic review on three American Jurisprudence texts, in the search for associations and dissociations registered in them about the research methodology applied to Law. The method undertaken is that of successive approximations, with the deconstruction of a Deridarian matrix. The review is used to approximate the proposed discursive techniques, in order to produce assertions common to the examined authors. It concludes with the critical signaling of the relevance of the works and the Jurisprudence current for the study of the Philosophy of Law, considering the vocation of its cultivators for the concrete solution of life issues.
\end{abstract}

KEYWORDS: methodology; research; law; pragmatism; deconstrutivism.

1 Trabalho submetido ao III Encontro Virtual do CONPEDI em 16/04/2021; aprovado para apresentação no Encontro em 31/05/2021; aprovado para publicação na Revista de Argumentação e Hermenêutica Jurídica em 05/07/2021; formatado e submetido à Revista em 13/07/2021.

2 Mestre em Direito Público e doutorando (Universidade Federal da Bahia). Professor universitário e advogado. Membro do Conselho de Fazenda Estadual (CONSEF). Artigo inspirado nos debates promovidos pelos Profs. Drs. Nelson Cerqueira, Rodolpho Pamplona Filho e Saulo José Casali Bahia, ao longo do curso de mestrado. Agradeço ao Prof. Edilton Meireles pelas contribuições. Salvador - Bahia - Brasil. prof.hsoliveira@gmail.com 


\section{INTRODUÇÃO}

O presente estudo é uma tentativa de associar três pensadores do direito no âmbito da tradição norte-americana, tendo por foco um trabalho específico da obra de cada um deles, e tendo por meta extrair desses três trabalhos um instrumental metodológico a ser desenvolvido como base epistêmica para o estudo e a pesquisa no âmbito do direito, com inspirações do Realismo Jurídico e no Pragmatismo Filosófico.

A meta desdobra-se em duas: examinar o desconstrutivismo de Balkin, de matriz assumidamente derridariana, e a aplicação por ele empreendida ao estudar o The Path of Law de Holmes; e extrair, por recurso ao desconstrutivismo balkiniano acerca da teoria do direito (como aplicado ao pensamento de Holmes), aportes metodológicos no discurso de Posner (que flagrantemente remonta-se a Holmes e a outros autores a que ele, Posner, denomina "pragmatistas"). Portanto, percebe-se que Holmes, aqui, entra como elemento de conexão entre os dois teóricos mais jovens.

Uma primeira dificuldade do projeto é empreender um estudo desconstrutivista sobre autores de volumosa produção intelectual (Balkin e Posner), produção essa que se espraia sobre diversos campos do conhecimento humano, muito além do direito e da teoria do direito. A estratégia para enfrentar tal dificuldade passa pelo de manter a atenção dirigida aos três trabalhos centrais da pesquisa. A referência a um ou outro escrito dos autores que não estritamente aos trabalhos objeto do estudo, ou que os comentam, complementam ou fazem contraste, sempre ocorre como suporte para a compreensão das três obras em foco, e não mais que isso.

Outra dificuldade reside nas distâncias que separam tanto a cultura jurídica brasileira daqueles escritos ora em exame, quanto a compreensão que cada um dos três autores parece elaborar sobre a metodologia da pesquisa em direito. Por "distância" quer-se significar não apenas o aspecto geográfico, mas, sobretudo, as diferenças de perspectivas, que apartam a vivência jurídica (seja profissional, seja teórico-acadêmica) no âmbito do common law, por um lado; da tradição de estudo e pesquisa desenvolvidos no âmbito do civil law, ou em países que tendem à transposição de raciocínios europeus-continentais (como no Brasil), por outro lado.

Apesar de referenciais comuns (o mundo cultural norte-americano, o liberalismo político, e o recurso às ideias de Holmes são apenas exemplos), também os autores ora em estudo se distanciam: o desconstrutivismo balkiniano direciona-se a reverenciar a preferência 
dos pensadores do direito pela aplicação de aportes filosóficos e metodológicos à teoria do direito; Posner denota ceticismo sobre tal postura metodológica, revigorando um discurso pró-empirista, mais aproximado à proposta de Holmes.

Os três autores (nos três trabalhos citados) parecem debruçar-se sobre um questionamento metodológico fundamental comum, a saber - de que modo se consegue apreender epistemicamente o direito? Evidentemente, as respostas dos autores passam pela particular visão sobre outra questão jusfilosófica fundamental - o que é direito? Pretende-se evitar, no presente estudo, maiores divagações sobre essa última pergunta (jusfilosófica), centrando as atenções na primeira (de cunho metodológico/epistemológico), e nos insights que os autores enunciam, e sem declinar de sólida literatura, estrangeira e brasileira, acerca da metodologia da pesquisa (com sua aplicação para o direito). Essa é, portanto, a estratégia que se pretende adotar para enfrentar aquela última dificuldade acima apontada.

Pretende-se concluir com um exame opinativo sobre os resultados alcançados pelos autores, no que se refere às considerações metodológicas ${ }^{3}$ e recursos de pesquisa por eles desenvolvidos. Tem-se, forçosamente, uma abordagem jusfilosófica de autores que, em certa medida, apimentam a teoria jurídica com algum ceticismo ou cinismo. Nossos estudos também propendem a uma visão algo cética sobre o "filosofismo jurídico"4 que diuturnamente desvia a atenção da teoria jurídica ou dos estudos do direito de seu (ou um de seus) problema(s) fundamental(is): a decidibilidade (FERRAZ JÚNIOR, 1980, p. 42-47).

\section{APRESENTAÇÃO E CONTEXTUALIZAÇÃO DOS AUTORES}

Holmes é uma figura marcante do cenário jurídico norte-americano, um dos mais citados juristas dentre os que integraram a Suprema Corte daquele país. Foi voluntário da infantaria do Estado de Massachusetts, atuante durante a Guerra Civil Americana (18611865). Fez seus estudos em direito após dar baixa no exército (1864) e dois anos depois (1866) veio a ser admitido no Bar. Em 1881, escreveu The Common Law, uma espécie de

\footnotetext{
Também maiores perquirições em torno da metodologia da pesquisa (ou da ciência) do direito escapariam ao objeto deste estudo. Bastam-nos as noções presentes em Karl Larenz (1997) e em Orides Mezzaroba e Cláudia Servilha (2019).

4 Colhe-se a advertência que Losano (2007, p. XLIII) adota para a sua própria obra como uma lição no direcionamento da pesquisa jurídica, mesmo no âmbito da teoria jurídica: "Dada essa propensão do direito para a realidade, este escrito tem uma relação difícil com a filosofia do direito, porque essa se distanciou dos direitos positivos. Nas filosofias do direito que me circundam não vejo raciocínios que, por indução, remontem aos temas mais gerais, partindo das normas positivas, e sim um confronto de discursos abstratos." Pois bem: se em certa medida concede-se, aqui, uma vitória ao confronto de discursos abstratos, noutra medida há de se ter em mente que o discurso preponderante é o da desconfiança a respeito de um método inteiramente calcado nesses confrontos e nessas abstrações, se absolutamente desconectado com esse corpus de conhecimento a que chamamos de direito.
} 
coletânea de aulas fortemente calcadas em decisões judiciais, sobre em diversas áreas do direito ${ }^{5}$. Em 1882 tornou-se professor da Harvard Law School, mas logo a deixou, no mesmo ano, para se tornar juiz da Supreme Judicial Court of Massachusetts. Fê-lo, entretanto, sem abandonar os discursos e artigos acadêmicos. Galgou a Suprema Corte dos Estados Unidos em 1902, e sua crítica ao formalismo e ao positivismo jurídico legalista, dentro e fora dos julgamentos, tornaram-se marcas registradas, tanto quanto a sua fama de "grande dissidente", graças à força argumentativa de seus votos-vencidos ${ }^{6}$.

The Path of Law (1897), portanto, é um desses trabalhos desenvolvidos durante o tempo de serviço junto ao Tribunal de Massachusetts, quando o autor contava com 55 anos de idade, antes de ascender à Suprema Corte. Apresentado à Faculdade de Direito da Universidade de Boston como um discurso (ALSCHULER, 1997, p. 354), é possível elencar, ilustrando com passagens, algumas ideias muito claramente expostas por Holmes em seu texto, e que se constituem em marcos do seu pensamento.

Diz-se que um dos conceitos holmesianos que mais perduram é aquele que se faz pela distinção entre bad man e good man (ALSCHULER, 1997; LEVINSON; BALKIN, 1998, p. 1). Convém destacar que, a despeito de tantos outros usos que a teoria jurídica ou a teoria social nos Estados Unidos fizeram dessa ideia maniqueísta a ponto de corroborar a sua vulgarização ${ }^{7}$, Holmes utiliza a figuração de um modo muito menos central e muito menos relevante do que aqueles que a repetem fazem transparecer. A figuração é um suporte para destacar que a linguagem jurídica está “infelizmente" recheada de expressões advindas da moral, mas que moral e direito não se confundem; e até se deveria cuidar, no intuito de uma melhor compreensão e aprendizado do direito, para que essas aproximações de linguagem se reduzissem ao máximo.

Para ser fiel ao texto de The Path of Law, destaca-se a clareza de seus principais objetivos. O primeiro deles já foi visto: distinguir direito de moral, e esse é um projeto com o

5 Para uma apreciação da obra de Holmes (2011) e sobre a influência da Escola Histórica, v. artigo de David Rabban (2003).

6 O tom crítico, cínico, ácido - contudo, polido, aristocrático -, as pinceladas de hedonismo em seu texto, a história de vida de ex-combatente do Justice Holmes, sua influência em Emerson, em Nietzsche, suas viagens rotineiras à Inglaterra e seu vínculo com a vida cultural daquele país nos lembram o personagem de Oscar Wilde, o Lord Henry Wotton, em $O$ Retrato de Dorian Gray.

7 Uma peça ilustrativa é o discurso proferido pelo $44^{\circ}$ Presidente dos Estados Unidos no dia $1^{\circ}$ de maio de 2011, por ocasião da operação militar que capturou e matou Osama Bin Laden (OBAMA II, 2011). A certa altura, os militares envolvidos na operação são chamados de "small team of americans [...] with extraordinary corage and capability", ao passo que "justice has been done" uma vez que o líder da Al-Qaeda era "a terrorist who was responsable for a murder of thousands". Fica evidente no discurso trabalha uma dicotomia "homem mau" / "homens bons" para a justificação de uma operação deliberada de assassinato. O que nos chama a atenção é o fato de que essa dicotomia, em um discurso dirigido ao povo americano (e ao mundo), a um amplo auditório, portanto, parte da premissa de que existem, na "natureza", "homens bons" e "homens maus" e, mais ainda, que essa é uma verdade meridiana, evidente para qualquer ser humano. 
qual se associam os juspositivistas do século XIX e XX, de diversos estratos e diversas tradições $^{8-9}$. Holmes é um exemplar do "realismo comportamentista", como o rotula o próprio ROSS (2000, 97-100), e comunga desse projeto juspositivista de distanciar o direito, o seu estudo e a sua linguagem de tudo aquilo que não é direito (notadamente, a moral, a política, a psicologia, a sociologia).

Ainda com fidelidade ao texto, o outro projeto declarado de Holmes é o de afastar a crença de que apenas por meio de recursos da lógica e do formalismo lógico se pode fazer bom estudo e ter boa compressão do que seja direito. $\mathrm{Ou}$, em suas palavras, pretende afastar uma segunda falácia: "the notion that the only force at work in the development of the law is logic" (HOLMES JUNIOR, 1897, p. 465). O autor demonstra que o ensino jurídico é o grande causador desse mal, pois juristas são exaustivamente treinados em lógica (presentes na analogia, na dedução, na linguagem das decisões judiciais etc.).

Entretanto, se a formação jurídica contivesse mais de economia e mais de estatística (e, aqui, Holmes mostra-se essencialmente útil aos cultores da Análise Econômica do Direito), esse mal talvez não mais estivesse presente.

Nessa linha é que o autor em estudo advoga a tese (bastante questionável em termos de coerência, como se verá mais adiante) de que estudar o direito (Law) e teoria do direito (Jurisprudence) passa muito mais por um estudo aprofundado, minudente, analítico estudo dos dogmas do sistema jurídico em exame (o norte-americano) do que o estudo de outros sistemas (como o Romano Antigo). Do mesmo modo, em lugar de se buscar a "quintessência" própria de todo e qualquer sistema, é melhor a busca de uma "anatomia acurada" do sistema em exame (HOLMES JUNIOR, 1897, 475).

O que desaponta e causa alguma dificuldade de compreensão, na parte final do The Path..., é que o autor se recusa de modo explícito a indicar qual seria o instrumental adequado para esse estudo. Ou seja, o trabalho de Holmes limita-se, do ponto de vista metodológico - e nisso é justo -, a apontar equívocos (recurso recorrente à linguagem da moral; crença exacerbada em recursos de lógica formal; recurso a institutos jurídicos de outros sistemas, em detrimento do exame analítico do direito positivo) e indicar alguns sinais para contornar esses

8 Como bem salienta Alaôr Café Alves, ao introduzir a tradução para o Português do direito e Justiça (ROSS, 2000, p. 9 14), em linha com Bobbio (1995, p. 144-146) e Barzotto (2007, p. 16).

9 Posner entende que esse tema em Holmes é uma "heresia" contra a fé pragmática (POSNER, 2007, p. 325), pois evidencia um forte positivismo jurídico, uma tentativa de banir termos morais do direito. Segundo Posner, "[o] direito não pode ser reduzido a regras claramente formuladas em leis ou constituições, ou a regras mais afirmações arbitrárias de vontade. Boa parte do direito aplicado pelos juízes, par anã mencionar o 'direito' que nos diz se as regras ou, a esse respeito, os próprios juízes estão em conformidade com o direito, consiste em considerações morais e políticas." (POSNER, 2007, p. 326). 
equívocos (estudo instrumental de economia e de estatística; cuidado metodológico nas etapas de análise e generalização; confronto histórico e confronto de custo/benefício nas decisões).

Ou seja, Holmes recusa-se a indicar tecnologias, ou "detalhes práticos" de como fazê-lo, pois - eis a conclusão do discurso - o autor está a tratar de teoria, e não desses detalhes práticos. A teoria longeva e influente é mais valiosa, segundo afirma Holmes, que a riqueza de meios materiais (HOLMES JUNIOR, 1897, 475-478) - uma conclusão em tom bem mais romântico que o cinismo prometido no início do texto, conforme anotado por diversos articulistas mencionados por Alschuler (1997, p. 354). A influência de Nietzsche em Holmes é, quiçá, a raiz das suas contradições (ALSCHULER, 1997, p. 361) ${ }^{10}$.

Jack Balkin é professor de Direito Constitucional na Universidade de Yale (tendo sido professor em variadas escolas de direito nos EUA e em outros países), com Ph.D pela Cambridge University e graduação em direito pela Harvard University. Balkin desenvolve trabalho autêntico por meio do weblog "Balkinization"", contando com a colaboração de diversos acadêmicos nos comentários sobre política e sobre direito. É também o fundador e diretor de um centro multidisciplinar de estudo do direito na Faculdade de Direito da Universidade de Yale, com estudo no direito e sua interface com as novas ferramentas de tecnologia da informação ${ }^{12}$.

No texto objeto do presente trabalho (LEVINSON; BALKIN, 1998), também um discurso elaborado para a Boston University e em homenagem ao centenário do discurso de Holmes, desenvolve-se a tese de que a dicotomia explorada por Holmes - ente "bad man" e "good man" - não representa com fidelidade as ideias do próprio Holmes. Melhor seria, defendem os autores, que a expressão fosse substituída pela ideia de "self-reliant", desenvolvida por um dos autores de grande influência intelectual sobre Holmes, Ralph Waldo Emerson.

A exposição de Levinson e Balkin parte das inconsistências decorrentes de um exame aprofundado da metáfora holmesiana. Holmes afirma que o direito, para ser bem

10 Posner corrobora as contradições internas do The Path... sinalizando, por exemplo, que a sua conclusão pela necessária apropriação de princípios econômicos ao direito é uma enunciação de um princípio moral, em rota de colisão com sua rejeição de qualquer proximidade entre moral e direito (POSNER, 2007, p. 324).

11 <http://balkin.blogspot.com/>, acessado em diversas ocasiões ao longo da confecção deste trabalho. Intuitivo refletir sobre a proximidade sonora da expressão "balkininzation" com "balkanization" (balcanização, em Português), ou seja, o processo de divisão política pelo qual passou a Península Balcânica com a derrocada o Império Austro-húngaro nas imediações da Primeira Guerra Mundial. Um processo repetido com a queda da "cortina de ferro", no quartel final do século XX. Em outras palavras, a expressão, via aproximação sonora, é uma metáfora de fracionamento, desconstrução.

12 V. notas biográficas no website do próprio Balkin, hospedado pelo portal da Yale University: http://www.yale.edu/lawweb/jbalkin/bio.htm, acesso em 2 jul. 2014. 
estudado e compreendido, deve ser examinado sob a ótica do homem-mau ${ }^{13}$, já que o homembom age motivado por "vagas sanções de consciência" (HOLMES JUNIOR, 1897, p. 459). Levinson e Balkin exploram, então, a associação binária e estruturalizada - "good man" / moral vs. "bad man" / direito - para questionar as diversas implicações que essa divisão acarreta para um positivista (no sentido de rejeição às ideias de Direito Natural) da envergadura de Holmes.

Para citar exemplos: a) a dicotomia não se sustenta intrinsecamente: essas duas figuras se assemelham essencialmente, já que ambos agem motivados por sanções e uma figura se dilui na outra (LEVINSON; BALKIN, 1998, p. 5), ou se diluem na conhecida figura idealtípica do egoístico homo economicus (LEVINSON; BALKIN, 1998, p. 3); b) figuras dicotômicas se autorreferenciam, de modo que o "bad man" é tão importante no discurso do Holmes quanto o "good man"; c) considerando que nem sempre a lei é "justa" ou "ética" um postulado que o juspositivismo latente de Holmes tem de aceitar, e o faz sem dificuldade -, é possível que o "good man" se recuse a seguir a lei injusta, e não seja tão "cordeirinho" de seguir a lei, por considerá-la "justa” apenas por ser lei. Desse modo, a posição de complicador do "bad man" se inverte com a do "good man", e o comportamento daquele se torna bem mais previsível do que o desse; e mesmo aquele, com todo seu egoísmo, pode estar mais predisposto a seguir a lei - para obter seus propósitos e ganhos pessoais - do que esse - por objetar, por sua consciência, seguir preceitos que contrariam suas convicções morais (LEVINSON; BALKIN, 1998, p. 9).

Acrescente-se aqui uma crítica de Aschuler (1997, p. 372), que nos parece muito angusta e pertinente: dentro da coerência do texto de Holmes, um "homem mau" de verdade não estaria em nada preocupado sobre o que diriam os tribunais sobre tal ou qual comportamento, e sim sobre o que faria o sheriff, com ou sem ordens advindas dos tribunais; esse sim, o sheriff, teria reais meios efetivos de atrapalhar a vida do "homem mau"...

Segue-se uma exposição do conceito emersoniano da pessoa "self-reliant"14. Primeiramente, os autores demonstram a importância de Emerson para a formação intelectual de Holmes, com citação de fatos históricos, de declarações colhidas da correspondência de Holmes, e de figurações utilizadas nos discursos do grande Justice. Afirmam que o "self-

13 Para ser fiel ao texto de Balkin, é necessário destacar que o autor rejeita o caráter sexista das expressões, e por isso as usa apenas entre aspas (LEVINSON; BALKIN, 1998). Teria preferido seguramente expressões como "pessoa boa" (good person) / "pessoa má" (bad person).

14 Com tradução um tanto difícil para o Português, considerado os usos já consagrados no direito e na filosofia para as possíveis versões. "Autônomo" ou "independente" já são expressões desgastadas para diversos fins. "Autossuficiente" parece-nos a expressão mais adequada. 
reliant" de Emerson, segundo a leitura dos autores em estudo, teria sido uma melhor metáfora que a do "bad man", uma melhor escolha para o texto de Holmes, de modo a que as ideias do próprio Holmes se tornassem menos contestáveis e mais holmesianas.

Levinson e Balkin expõem a noção emersoniana de self-reliance associando-a ao Ubermensch de Nietzsche. O self-reliant age conforme a sua consciência, e o papel de sua adequação ao direito é mais reduzido que o papel de sua adequação ao justo. É um conceito que pode parecer um tanto difícil de ser "digerido" em tempos nos quais a construção social da realidade anda tão consolidada, afirmam, mas que faz sentido ainda hoje se entendida como espontaneidade, questionamento das ideias arraigadas no passado, busca por perspectivas calcadas no futuro.

Em outras palavras: dentro da coerência interna do discurso de Holmes, afirmam Levinson e Balkin, melhor seria pensar que o estudo do direito deve-se dar sob a perspectiva do homem autoconfiante, que age conforme suas convicções (sejam elas altruístas ou egoístas). Com a devida licença, e este talvez não seja o melhor momento para desenvolver as minhas convicções pessoais, parece-me que a extrapolação vai muito além da coerência interna do texto de Holmes.

Uma leitura repisada do The Path... nos conduz à mesma convicção a que chegou Robert W. Gordon (apud ALSCHULER, 1997, p. 361): para um discurso dirigido a estudantes, sua fala é muito mais bem compreendida como uma figura de linguagem, uma provocação, em um discurso não necessariamente devotado a ser consistente, analítico, coerente, rigoroso. Como já se pode anotar, "law" no texto aparece às vezes como "atividade prática", uma "profissão" (HOLMES JUNIOR, 1897, p. 459), às vezes como "atividade teórica", e às vezes como o "objeto" (como fariam KELSEN, 1998, p.1; ROSS, 2000, 40-41; REALE, 1998, p. 303-305 etc.) de uma delas, qualquer coisa como um "todo coerente de significação e motivação", como em Ross.

Esses momentos (menos frequentes do que os leitores de Holmes sugerem) residem em asserções como "prophecies of what the courts will do in fact" (HOLMES JUNIOR, 1897, p. 461). Não há dúvida de que no discurso textual de Holmes, a metáfora possui maior afinidade (como exortação a que não se busque compreender o direito pelo recurso a ideias moralistas, contingentemente presentes nas linguagens das leis e das sentenças) com aquelas proferidas por Rui Barbosa, como a exortar aos estudantes futuros magistrados (BARBOSA, 1999, p. 40). 
Levinson e Balkin propõem uma desconstrução da dicotomia bad man / good man, uma ideia importante e renitente (embora periférica, conforme já salientado acima) no The Path..., desestruturando, assim correntes de críticos de Holmes. Com todas as coerências ou incoerências internas, o fato de um artigo escrito há mais de cem anos ainda suscitar provocações, inquietações, defesas, releituras e debates, por certo o credencia como um documento a ser considerado no âmbito dos trabalhos de teoria do direito desenvolvidos no seio ou no entorno da cultura jurídica norte-americana.

Richard Posner é professor de direito da Universidade de Chicago desde 1969, tendo atuado também em Stanford. Graduara-se em Harvard em 1962, sem jamais deixar seu vínculo com a academia. Paralelamente, exerceu no início funções de assistente jurídico e advogado no setor público. Foi presidente da Lexencon Inc. entre 1971 e 1981, uma respeitável consultoria econômica norte-americana, de atuação global, com ênfase no tratamento de dados relevantes para o cenário jurídico. Passou a integrar a magistratura em 1981 (Court of Appeals for the Seventh Circuit), tendo exercido a função de Presidente do Tribunal entre 1993 e 2000 . Aos mais de oitenta anos de idade, segue atuando como senior lecturer da Faculdade de Direito da Universidade de Chicago e, paralelamente, como magistrado ${ }^{15}$.

Posner é um dos pilares do movimento denominado Law \& Economics (ora referida como “Análise Econômica do Direito", ora como "L\&E”, ora como "AED”, ente outros acrônimos $)^{16}$. Desse modo, como um dos pilares do movimento, é que o autor é tratado por Caliendo (2009, 11-64), ao lado de Coase, Buchanan, Mises e Douglas North. Sua contribuição é muito vasta, seja por redigir a primeira obra sistemática sobre o tema ${ }^{17} \mathrm{e}$ postular a sua influência sobre todas as áreas do direito, seja por identificar a função econômica do direito como "forma de estímulo ou desincentivo a determinadas condutas", “modifica[ando] a modulação dos incentivos” (CALIENDO, 2009, p. 47).

Dentro de sua vasta produção intelectual, pinçam-se obras de cunho jusfilosófico e metodológico, e, dentre elas, The Problems of Jurisprudence, publicado pela Harvard University Press em 1990 (POSNER, 2007). Ali o autor debate as diversas aproximações teóricas do direito, categorizadas inicialmente (de modo não excludente) entre "Formalismo", "Realismo", "Direito Natural" e "Direito Positivo". Aproxima alguns modelos marcantes

$15 V$. notas biográficas no website do próprio Posner, hospedado no portal da University of Chicago Law School: http://www.law.uchicago.edu/faculty/posner-r, acesso em 13 jul. 2021.

16 Para uma introdução à Análise Econômica do direito sugere-se, dentre outras obras, o texto de Cooter e Ulen (2010). Para um estudo das interações estratégicas ínsitas na Análise Econômica do direito, sugere-se a obra de FIANI (2009).

17 Economic Analysis of Law, de 1973 (v. POSNER, 2011). 
associados a esses rótulos (com os quais ele mesmo parece não estar muito de acordo POSNER, 2007, p. 14-17). Debate, dentre outras questões: o papel da lógica e da razão prática na teoria do direito (POSNER, 2007, p. 95-150); a concepção sobre o que seja direito para o pragmatismo jurídico, com especial ênfase no método genealógico crítico de Holmes e Nietzsche (POSNER, 2007, 321-327); abordagens de outros segmentos do conhecimento humano que têm a dizer sobre uma ideia de "justiça material", como a filosofia moral, a abordagem econômica do direito, a literatura (POSNER, 2007, 419-562).

No capítulo final do livro (POSNER, 2007, 607-627), o pensamento do autor é sintetizado em breve excerto, expondo as principais ideias desenvolvidas ao longo do livro. Segundo, por sua aproximação em relação às duas outras obras estudadas, seja do ponto de vista de sua dimensão (cerca de 20 páginas), seja pelo suposto caráter exortativo que o título "um manifesto" sinaliza. Caráter exortativo comumente presente em textos redigidos como discursos, a serem proferidos em palestras.

A proposta assumida por Posner é de pôr a nu as limitações da filosofia, quando se tem por tema o estudo do direito, evidenciando o embate entre o pragmatismo filosófico (que o autor professa, em meio aos estudos de Peirce, James, Holmes, Dewey, Mead, Schiller; Rorty, cultores dos Estudos Jurídicos Críticos e do feminismo - POSNER, 2007, p. 618) e a filosofia analítica (à qual podem ser associados o Positivismo Lógico, a filosofia da linguagem posterior à "virada linguística"). Esse embate, afirma Posner (2007, p. 621), não se faz de modo tão claro, pois ícones da filosofia analítica como Wittgenstein, Popper e Habermas afinaram seus pensamentos com aqueles próprios do pragmatismo filosófico. Também indica (e diferencia) as diversas vertentes que podem ser classificadas como "pragmatismo filosófico".

Posner rejeita um formalismo extremado - aquele que leva às últimas consequências a ideia de "conceber o direito como um sistema de relações entre ideias, e não como uma prática social” (POSNER, 2007, p. 608). Aqui sua aproximação com Holmes é evidente, pois Posner admite que o direito é (também) uma prática social.

Rejeitar um formalismo extremado ${ }^{18}$ implica, por conseguinte, denunciar as limitações de aproximações lógicas, filosóficas e científicas sobre o direito. Para Posner, não existe tal coisa como um "raciocínio jurídico". Os recursos de que dispõem aqueles que lidam com a linguagem jurídica são os mesmos (POSNER, 2007, p. 613). Nesse sentido, a

18 "Rejeito o formalismo exagerado que considera as relações entre as ideias jurídicas como a essência do direito e do pensamento jurídico." (POSNER, 2007, p. 608). 
racionalidade é muito pouco útil em momentos cruciais da vida jurídica, como o das mudanças do direito, já que o papel da emoção provocada por um discurso persuasivo é preponderante $^{19}$.

Disso decorre que Posner associa-se à ideia holmesiana de que a melhor concepção sobre o que seja o direito (e, portanto, a melhor maneira de aproximar-se epistemicamente dele) é vê-lo como uma "atividade", e não como um "corpus" (POSNER, 2007, p. 614).

Por fim, reafirma-se o caráter "funcional" do direito. Vale dizer, a depender da matéria regulada, do campo do comportamento humano em jogo, não se pode descurar do aporte adequado de recursos advindos de outros campos do saber humano (POSNER, 2007, p. $615)$.

Eis, em breves aforismos, as principais questões desenvolvidas por Posner sob o influxo de uma inspiração pragmatista do mundo e do conhecimento do mundo, uma visão que desmonta a estrutura estática, composta por um sujeito cognoscente passivo e uma realidade objetiva e estática. Uma visão que conduz à problematização da própria ideia de verdade, desontologizada (POSNER, 2007, p. 621-622).

Por fim, Posner caminha para o momento mais exortativo de seu texto, que curiosamente também se volta para o ensino jurídico, para a academia. Sua crítica se direciona à formação preponderantemente profissionalizante da academia norte-americana, em detrimento de "investigações sistemáticas sobre as causas e as consequências do direito" (POSNER, 2007, p. 625). É à academia que compete o papel, por ausência de outros foros, de desenvolver esses estudos, sem amarras epistemológicas indeléveis.

No lugar de verborragia pouco empírica e pouco original, Posner prenuncia (bem em linha com Holmes) um estudo acadêmico que se valha de "modelos matemáticos", "análise estatística", "coleta de dados e experimentação", "o conhecimento das instituições jurídicas nacionais e estrangeiras", além de recursos das ciências afins como economia, ciência política, estatística, filosofia, psicologia, ética científica (POSNER, 2007, p. 626).

19 Entretanto, perguntar-se-ia: em que campo do saber se há de negar em sua integralidade o papel da emotividade, do subjetivismo, das motivações pessoais nas escolhas cruciais? KUHN (1998), citado pelo próprio Posner (2007, p. 620) já o enunciara em termos de filosofia da ciência. Por que negligenciar ostensivamente o papel epistêmico de uma aproximação retórica sobre o direito (POSNER, 2007, p. 97), em uma corrente que encontra cultores em tantas tradições jurídicas, tão distintas, como a europeia-continental (ALEXY, 2013; PERELMAN; OLBRECHTS-TYTECA, 2005), a europeia-insular (MACCORMICK, 2008), e a brasileira (ADEODATO, 2011)? Se o direito é uma atividade, e uma atividade que não pode descurar de seu aspecto "retórico", por que negligenciar a função epistêmica do estudo da retórica? 


\section{RUMO À DESCONSTRUÇÃO DO MANIFESTO PRAGMÁTICO}

Não vejo como classificar ou perscrutar no "desconstrutivismo filosófico" um método. Seria um contrassenso. Parece mais coerente assimilá-lo com uma postura, uma postura crítica, ácida ${ }^{20}$, de questionar ideias pré-concebidas e de resgatá-las - não propriamente abandoná-las - mediante a utilização de algumas técnicas. Do contrário, seria mero niilismo, e não nos parece possível associar puro negativismo da atividade racional cognoscente à ideia de um método científico (se entendido como um caminho para atingir-se racionalmente o conhecimento).

Nesse sentido, o The Path... possui um quê desconstrutivista quando desfere o golpe contra o discurso moralizante do e no direito (repita-se, um projeto em nada inovador) por meio da desconstrução de um estereótipo. Como se dissesse: "não me venha falar do "cara bonzinho' quando o assunto é o direito, pois se é possível buscar nesses estereótipos algum instrumental para pensar sobre como os tribunais decidirão uma questão, é preciso pensar como o "cara mau"”.

Não há nisso um método, mas uma postura. Uma postura que permeia a história das ideias desde que o primeiro sofista desconfiou da verdade, ou desde que o Sócrates platônico ousou desafiar as convicções de Trasímaco. Postura que instigou Descartes a desconfiar de suas convicções; que incitou Bacon, à mercê do seu discurso empirista, a conclamar à "citação perante o intelecto" dos dados da natureza; ou que anima a todos que comungam, com Posner, alguma inspiração realista.

Dito isso, cabe questionar: Holmes, Balkin e Posner nos sinalizam algum método para a pesquisa em direito, ou alguma aplicação peculiar da metodologia da pesquisa ao estudo do direito?

Holmes, quiçá o autor mais "positivista filosófico", ou mais "estruturalista”, dentre os três, ao menos nos oferece um caminho "para adquirir uma visão liberal do assunto". Na passagem já transcrita mais acima (HOLMES JUNIOR, 1897, p. 475), o autor afirma que para ir ao fundo do assunto não é preciso ler "outra coisa" (refere-se ao estudo do direito em outros países), e sim: (a) seguir o caminho da generalização do "corpo atual dos dogmas", com recursos da teoria do direito; (b) por recurso à História, compreender como os temas "generalizados" chegaram ao seu estado; (c) a partir das finalidades que as regras adotadas

\footnotetext{
20 Para usar a mesma figuração de Holmes, de mergulhar a noção de "dever" no "ácido do cinismo": "You see how the vague circumference of the notion of duty shrinks and at the same time grows more precise when we wash it with cynical acid and expel everything except the object of our study, the operations of the law." (HOLMES JUNIOR, 1897, p. 462).
} 
pretendem atingir, e as razões históricas pelas quais tais fins foram erigidos, questionar os custos e benefícios desses fins e da adoção dessas regras. Daqui, certamente, decorre a afirmação de que Holmes adota um "método genealógico crítico" aproximado ao de Nietzsche (POSNER, 2007, 321-327).

Entretanto, problematizando a noção acima exposta, é confuso, em meu sentir, entender de onde vem esse "corpo atual de dogmas", se considerarmos que o direito é uma "atividade de prever a incidência da força pública por meio dos recursos instrumentais dos tribunais" (HOLMES JUNIOR, 1897, p. 457, em tradução livre). Qual é a fonte dessas predições? O "body of reports, of treatises, and the statues, in this country and in England" (HOLMES JUNIOR, 1897, p. 457)? Esses seriam, como afirma, os "meios", mas não o "objeto" de estudo? Se sim, como definir, como encontrar esse "corpo de predições"? Em suma, de onde emanaria um "corpo de predições" apropriado ao estudo? De cada estudioso?

Parece-nos, com a devida licença, que essas perguntas, se efetivamente foram bem formuladas neste presente trabalho, ficam sem resposta no seio do realismo jurídico norteamericano, ou pelo menos dentro da obra de Holmes. De tal modo que não vemos, na obra estudada, qualquer contribuição muito inovadora em relação à metodologia da pesquisa.

Entrementes, um melhor exame nos parece necessário em relação à parte final da asserção de Holmes, na passagem acima referida, aquele trecho em que ele afirma:

(...) and, finally, so far as you can, to consider the ends which the several rules seek to accomplish, the reasons why those ends are desired, what is given up to gain them, and whether they are worth the price. (HOLMES JUNIOR, 1897, p. 476)

Valorar "preço" e "sacrifício" no atingimento de fins, por meio das regras (jurídicas). Ora, parece-nos aqui um debuxo da noção de "ponderação", tão creditada a Dworkin (2002, p. 127-203) ou a Alexy (2013, p. 94-99).

Voltando-nos ao exame de Balkin, parece intuitivo partir de um texto mais geral do autor a respeito do desconstrutivismo do que aquele que ora examinamos. Em Deconstruvctive Practice and Legal Theory, o autor afirma:

By the term 'deconstruction', however, I do not have in mind merely stinging criticism, but specific techniques and philosophical ideas that Derrida and his follower have applied to various texts. These techniques often do involve teasing out the hidden antinomies in our language and thought, and that is primarily how I came to be interested in them. (BALKIN, 1987, p. 2).

Retornando ao The 'Bad-man'..., é possível afirmar que essas técnicas foram empregadas para desmontar uma ideia arraigada, de que a dicotomia bad man / good man 
essencial à compreensão de Holmes. Em seu lugar, introduz-se o conceito emersoniano de self-reliant (ou seja, subtrai-se uma ideia dicotômica e introduz-se um estereótipo presumidamente não dicotômico).

Com isso, mais do que mostrar um método de pesquisa no direito, Balkin (e Levinson) nos lega(m) uma recomendação, a meu ver: não se devem abandonar os textos clássicos; mas não se deve furtar de questionar tais textos clássicos dentro de todas as suas possibilidades interpretativas, liberando o texto do seu autor. Nesse sentido, as técnicas de desconstrução, advindas da crítica literária derridariana, podem seguramente ser compreendidas como técnicas de interpretação de texto - inclusive do texto jurídico, dos documentos jurídicos, daquilo que é enunciado no âmbito das atividades práticas jurídicas.

A desconstrução, convém reafirmar, não se assemelha a um método, mas sim a uma postura, combinada com a adoção de uma série de técnicas (p. ex., inversão de hierarquias). Essa postura parte da ânsia pela busca de uma compreensão aprofundada do texto (em um sentido amplo para “texto") - uma busca que Holmes também assentara.

Em Posner, as considerações metodológicas parecem mais esparsas. O grande ponto de Posner, examinando-se o conjunto de sua (extensa) obra, e posto de modo quiçá excessivamente simples, pode-se resumir na seguinte afirmação: a economia tem (muito) a dizer sobre o direito e o seu estudo. Em um grau de abstração mais elevado, portanto, tem-se que a autonomia do estudo do direito e do próprio direito é contestável. A busca por um método para o estudo e pesquisa do direito, portanto, seria disparatada.

Um ponto (pragmatista) está na desmistificação da busca em alcançar a verdade. A verdade em Posner (e, segundo ele, nos pragmatistas) é muito mais instrumental. Afinal:

\footnotetext{
Se não há verdade lá fora, isso nos deveria deixar particularmente desconfiados das pessoas que afirmam tê-la encontrado, e que argumentam que novas investigações seriam fúteis ou subversivas, devendo-se, portanto, proibi-las. [...] Há conhecimento mesmo que não haja verdade suprema, e uma teoria falibilista do conhecimento enfatiza, como precondições para o desenvolvimento do conhecimento científico e de outras modalidades do conhecimento, a contínua verificação das "verdades" aceitas, o contínuo repúdio às vacas sagradas - em suma, um compromisso com a indagação livre vigorosa, sem que lhe peça ou forneça procedência intelectual. (POSNER, 2007, p. 623-624).
}

O texto de Posner utiliza recursos desconstrutivistas. O plano geral do Problemas de Filosofia do Direito (2007) parece elaborado como uma tática desconstrutivista voltada contra a filosofia analítica: no prefácio, Posner agradece "ao falecido Paul Bator, que ao resenhar um de meus livros referiu-se a mim como um escritor 'preso a uma epistemologia superficial insatisfatória"”, e afirma que essa crítica o levou a examinar problemas da filosofia 
do direito com maior profundidade (POSNER, 2007, p. XVI). Parece-nos que Posner aprofundou seu estudo, de "métodos da filosofia analítica" (POSNER, 2007, p. 607) com um claro intuito de desconstruí-la - quiçá implodi-la.

Posner parece adotar (deliberadamente) uma estratégia equiparável à de Ulisses e seu cavalo (engenhosamente), e à de Diogo Álvares Correa (intuitivamente): imiscuir-se no campo adversário para salvar sua pele e dominar terreno que lhe fora negado. Posner rende homenagens aos filósofos formalistas, como chama, ao usar a "filosofia analítica" para detonar a filosofia analítica como instrumental de estudo do direito. Posner evoca poderes místicos a partir de seu instrumental, faz mira com seu bacamarte consequencialista, flerta e desposa ideias formalistas, para firmar uma preponderância de suas inspirações no realismo holmesiano.

Segundo Posner, é questionável que exista um raciocínio jurídico apto a direcionar a tomada de decisão, e é questionável que se possa direcionar o estudo do direito a uma busca pela objetividade, vale dizer, por um sentido objetivo único de racionalidade na tomada de decisão. Implicitamente, portanto, Posner pretende ter usado a filosofia (não pragmática, não voltada a consequências, excessivamente idealista) para catapultar do estudo do direito uma visão monocular e bidimensional do direito, dos recursos materiais para o seu estudo, e dos métodos empregáveis para o seu estudo.

No entanto, Posner não se livra integralmente de ideias estruturalizadas e estruturalizantes. Seu texto é recheado delas.

Uma ideia algo confusa, mas evidentemente presente em Holmes é aquela que embaralha a dicotomia "estudioso do direito" / "praticante do direito". Parece que tal amálgama deflui da obra de contemporâneos de Holmes (como Roscoe Pound). Essa dicotomia, contudo, parece corrente na história das ideias jurídicas desde ao menos o século XIX, embora jamais tenha sido vivenciada claramente.

Dicotomia similar no Brasil é aquela usualmente presente mesmo em noticiários: por um lado, tem-se o "jurista” (em geral, o acadêmico, vinculado a uma instituição de ensino superior, especialmente os que não se dedicam à atividade acadêmica em seu sentido mais clássico: a "pesquisa" - mas também reivindicam esse rótulo os consultores, os pareceristas, os professores de cursos profissionalizantes ou estritamente ligados ao "ensino", os escritores de livros-texto), em oposição aos "operadores do direito" (sejam eles os que integram órgãos da ordem jurídica, sejam figuras que os circundam, os profissionais do direito: magistrados, membros do Ministério Público, advogados - públicos e privados -, e, mais recentemente, 
titulares de outros cargos públicos cujo acesso vem-se restringindo ao bacharéis em direito, como delegados de polícia, notários públicos, cúpula dos assessores da magistratura, certos assessores parlamentares etc.).

Parece, aliás, que essa dicotomia, em termos práticos, tanto nos EUA como no Brasil não se confirma diuturnamente na vida das pessoas. Quem se relaciona com o direito no mais das vezes assume (ou assumiu, ou assumirá em algum momento da vida, frequentemente em concomitância) o papel de "operador do direito" (praticante) e de "jurista” (estudioso).

Posner camufla a sua adesão aos conceitos holmesianos em relação ao estudo do direito e à prática do direito, mas deixa marcada a distinção entre "academia" e "praticantes". Ora, por quem os sinos dobram? A relação entre "academia" e os "praticantes" parece funcional, muito bem delineada, estruturada - algo que não se amolda a uma leitura atenta de Holmes e de suas ideias desestruturalizantes, pretensamente "subversivas". Tampouco a uma leitura atenta do próprio Posner, que parece sinalizar a desconstrução de estruturas como essa acima exposta.

É verdade que a academia americana (assim como a brasileira) volta-se excessivamente à formação profissional? Dir-se-ia que por aqui talvez não. Talvez, pensando em Posner e o consequencialismo dos atos decisórios, seu cuidado com dados empíricos e com técnicas e métodos não meramente literários, talvez se chegue à conclusão de que a academia brasileira fomenta excessivamente o estudo literário e filosófico, torce o nariz ao tratamento empírico, e debate-se por satisfazer os anseios profissionalizantes dos estudantes. São conjecturas. Somente dados empíricos e estatísticos nos conduziriam a um discurso mais consistente.

Ou seja, falta empirismo, penso eu, no discurso de Posner sobre as preferências dos advogados norte-americanos, sendo certo que aqui (e lá) os advogados (mais do que juízes e promotores) têm buscado aprender um pouco mais sobre práticas profissionais (em cursos de especialização lato sensu) e práticas administrativas (os Masters in Business and Administration - MBAs), além de cursos de curta duração de áreas afins à sua prática (contabilidade, línguas, psicologia etc.).

Outro ponto que nos parece saliente é o desapreço à hermenêutica, como um processo que se pretende ao menos lógico, se o projeto do autor (Posner) é essencialmente literário, e se vale, ainda que veladamente, de recursos da crítica e da hermenêutica literária (desconstrução) para associar ideias de autores. 
Ora, Posner manifesta-se em linguagem! Dizer-se que "não há mais um sentido útil em que o direito seja interpretativo [...] [pois] não há interpretações 'logicamente' corretas; a interpretação não é um processo lógico" (POSNER, 2007, p. 615) é algo ou muito hermético, ou, contrariamente, muito frívolo. A linguagem é lógica/semiótica (PEIRCE, 2005, passim); a atividade jurídica registra-se em linguagem; Posner manifesta-se em linguagem; logo (o uso da estrutura silogística por pura e deliberada, mas respeitosa, provocação), como desmerecer tanto assim a lógica? Como desmerecer tanto assim a hermenêutica? Como, sem hermenêutica, e sem recursos lógicos, poder-se-ia considerar as "consequências das decisões alternativas", senão por meio de predições calcados em processos, no mínimo, "quaselógicos"?

Não parece ser o mesmo Posner que anos depois veio a pregar a regulação do mercado de capitais norte-americano (POSNER, 2010a), após uma narrativa analítica da crise de 2007, e a pregar que para tanto se deve valer de um uso metódico de coleta e tratamento de dados. Bem, pode-se argumentar que esse último o trabalho citado não é de cunho jurídico, tendendo à ciência política (ou de política econômica). Entretanto, dentro das perspectivas posnerianas ou holmesianas, como sustentar o distanciamento dessas duas "coisas"? Não serão decisões (jurídicas) que, por recursos behavioristas (ou não), via indução, que evitarão a repetição da omissão das autoridades e da cúpula das instituições financeiras num futuro? Isso não representaria uma evolução do direito?

O que dizer, então, do significado, para Posner, da expressão "sistema jurídico" por ele empregada aos borbotões em seu texto, em diversas passagens, sem maiores considerações ou ressalvas? O que seria um "sistema"? Há algo de lógico em um sistema? É sobre o "sistema jurídico" que se debruçam os estudiosos do direito? A "atividade dos tribunais", ou a "atividade dos juristas" (e por que não a atividade dos delegados de polícia e dos sheriffs, dos auditores fiscais, dos conselheiros dos Tribunais de Contas etc.?) integram esse "sistema"?

Ocioso recordar que a noção de "sistema jurídico", ou da "natureza sistemática do direito", como muito bem pontua Raz (2012, p. 1-5), é uma das questões mais centrais dos teóricos classicamente associados a uma "filosofia analítica" do direito (e, por que não dizer, de uma filosofia do direito positivo, ou positivismo jurídico), a exemplo de Austin, Hart e Kelsen - em linha com Bobbio (1995, passim) e Barzotto (2007, passim) - e do próprio Joseph Raz. Admitir, ainda que de modo periférico, essa natureza sistemática implica, tendo em vista a história das ideias jurídicas, no mínimo o ônus de esclarecer como uma ideia tão 
formal não teria sido assim, de modo formalista, adotada em uma teoria que se pretende pragmática, ou realista.

Na mesma linha, que se pode dizer da ontologização da dicotomia, tão presente no "raciocínio jurídico" (nos arrazoados e nos tratados teóricos) norte-americanos e divulgada sem maiores perquirições ao longo do texto de Posner, ente "hard cases" / "easy cases"? Não se teria aqui uma estrutura - criticável e muito criticada em pelos pensadores do direito no Brasil (para um exemplo, STRECK, 2012, p. 296-326) -, formalizada e, como se disse, ontologizada? Para além de questionar a pertinência dessa dicotomia, indaga-se se faz sentido a Posner arrostar-se o papel de pragmatista e assumir como fora algo presente "no mundo" uma ideia que distancia casos, entre fáceis e difíceis.

Por esses exemplos, cremos que o descrédito de Posner para com a lógica e a epistemologia aplicadas ao direito não pode ser levada às últimas consequências.

\section{CONCLUSÃo}

Holmes, Balkin e Posner são autores renomados, com respeitoso e consolidado trabalho e para os quais a atenção de juristas de todo o mundo se voltam. No Brasil, contudo, não se tem notícia de estudos sobre a obra do segundo, ao passo que o primeiro e o terceiro são circunstancialmente mencionados em reforço de produção da velha dogmática jurídica. Os três possuem características comuns, das quais se decanta a forte argumentação por provocação, de inspiração cínica. Usar os recursos argumentativos, estilísticos e performáticos desses autores é, seguramente, render-lhe merecida homenagem.

Holmes, em seu The Path of Law (1897), apresenta um discurso vibrante, porém um pouco inconsistente, quando se inicia quase que como uma ode ao pragmatismo, conclama o estudo de economia e estatística, mas conclui como uma exortação à formulação de teorias, e um desmerecimento ao discurso voltado a "detalhes práticos". Ademais, demonstrou-se, há sem dúvida um discurso moralista e moralizante, dirigido aos estudantes, que não serão felizes apenas atingindo riquezas materiais, mas sim se conseguirem tornar seus discursos universais.

Balkin, co-autor de The 'Bad Man', the Good, and the Self-Reliant (1997), pretende aplicar técnicas desconstrutivistas para advogar a tese de que melhor do que a dicotomia "bad-man"/"good-man", seria mais adequada ao discurso de Holmes a apropriação do conceito emersoniano de "self-reliant". Demonstrou-se, sem deixar de louvar o estudo e as 
lições sobre desconstrutivismo, que a reconstrução que os autores propõem para o texto de Holmes não é fiel a algumas das propostas do próprio texto. Com efeito, um discurso que se iniciasse afirmando que para demonstrar que a linguagem da moral dissona da linguagem do direito, e que para prová-lo bastaria ver que o direito é voltado a conter o "autossuficiente", não provaria nada em relação à separação moral / direito. O discurso, certamente, seria bem mais enfadonho e inconclusivo. Nesse sentido, seguimos a tese de que essa dicotomia não é uma tese central de Holmes, e sim, muito mais, um recurso retórico, e firmamos postura cética em relação ao êxito, neste caso, da proposta de desvincular o autor do texto.

Posner, por fim, afirma-se pragmatista, influenciado pelo realismo jurídico de Holmes. Após a apresentação de algumas das ideias sintetizadas no capítulo final de seu livro Problemas de Filosofia do Direito (2007), capítulo esse intitulado "Um Manifesto Pragmático", demonstrou-se por meio do presente trabalho que as ideias ali desenvolvidas não se coadunam com um pragmatismo "a ferro e fogo". Louvando-se a brilhante defesa de que a teoria do direito e a dogmática jurídica (a rigor, essa distinção comum na tradição jurídica do Brasil não aparece, contudo, no trabalho de Posner) ganham ao se abrir às contribuições de outros saberes, dentre eles a economia, firma-se por outro lado uma severa descrença na desconsideração que Posner afirma fazer sobre os bons resultados que se podem auferir, no âmbito da teoria do direito, ou da dogmática jurídica (e mesmo na prática profissional), por recurso a instrumentais epistemológicos, lógicos, linguísticos, filosóficos e (por que não dizer) formalistas.

O diálogo epistemológico que se pretendeu travar a partir dos autores parece-nos profícuo. O recurso ao desconstrutivismo e à postura crítica são caminhos seguros para a evolução do conhecimento sobre o direito. O direito opera (assim como a religião) com dogmas, com certezas postas. Essas certezas, contudo, são questionáveis e frequentemente questionadas, não apenas no âmbito do debate puramente político, mas também no seio do debate jurídico (quer se dê em curso de uma relação jurídica processual, quer se faça sob a consulta que o anteceda; também no âmbito acadêmico). Tal e qual as certezas científicas.

Se é verdade que os debates (científicos, jusfilosóficos, jusdogmáticos, ou mesmo no curso de um processo judicial ou na discussão comezinha de uma aconselhamento profissional) se travam por recurso a infinitos meios (e, portanto, de modo não exaustivamente apropriável), não é menos verdade - sempre, com Posner, usando a palavra verdade como algo passível de questionamento - todo e qualquer meio (lógico, empírico, 
crítico, histórico, estatístico, hermenêutico, linguístico, axiológico etc.) é bem-vindo, na tentativa de apreensão cognitiva dos processos pelos quais se desenvolvem os debates.

Dar conta das possibilidades de uso desses recursos é o papel da epistemologia jurídica. Acredita-se que Posner desempenhou com maestria seu papel, ainda que, com licença e humildade, não estejamos totalmente de acordo com as conclusões do autor.

\section{REFERÊNCIAS}

ADEODATO, João Maurício. Uma Teoria Retórica da Norma Jurídica e do direito Subjetivo. São Paulo: Noesis, 2011.

ALEXY, Robert. Teoria da Argumentação Jurídica: a teoria do discurso racional como teoria da fundamentação jurídica. 3. ed. Rio de Janeiro: Forense, 2013.

ALSCHULER, Albert W. The Descending Trail: Holmes' Path of Law ons Hundred Years Later. Florida Law Review, v. 49, n. 3, p. 353-419, jul/1997. Disponível em:

http://chicagounbound.uchicago.edu/cgi/viewcontent.cgi?article=1849\&context=journal_article s Acesso em 14 abr. 2021.

BALKIN, Jack M. Deconstructive Practice and Legal Theory (1987). Faculty Scholarship Series. Paper 291. Disponível em: http://digitalcommons.law.yale.edu/fss_papers/291 Acesso em: 25 ago. 2017.

BALKIN, Jack M.; LEVINSON, Sanford. The 'Bad Man', the Good, and the Self-Reliant (1998). Faculty Scholarship Series. Paper 261. Disponível em:

http://digitalcommons.law.yale.edu/fss_papers/261 Acesso em: 22 ago. 2017.

BARBOSA, Rui. Oração aos Moços. 5 ed. Rio de Janeiro: Casa de Rui Barbosa, 1999.

BARZOTTO, Luís Fernando. O Positivismo Jurídico Contemporâneo: uma introdução a

Kelsen, Ross e Hart. 2 ed. Porto Alegre: Livraria do Advogado, 2007.

BOBBIO, Norberto. Positivismo Jurídico: lições de filosofia do direito. Tradução e notas de Márcio Pugliesi, Edson Bini e Carlos E. Rodrigues. São Paulo: Ícone, 1995.

CALIENDO, Paulo. Direito Tributário e Análise Econômica do direito: uma visão crítica. Rio de Janeiro: Elsevier, 2009.

COOTER, Robert; ULEN, Tomas. Direito \& Economia. 5. ed. Porto Alegre: Bookman, 2010. 
DERRIDA, Jacques. A Escritura e a Diferença. 2. ed. São Paulo: Perspectiva, 1995.

DWORKIN, Ronald. Levando os direitos a Sério. São Paulo: Martins Fontes, 2002.

FERRAZ JÚNIOR, Tercio Sampaio. Introdução ao Estudo do direito. 4. ed. São Paulo: Atlas, 2003.

FERRAZ JÚNIOR, Tercio Sampaio. Teoria da Norma Jurídica. 3. ed. Rio de Janeiro: Forense, 1999.

FERRAZ JÚNIOR, Tercio Sampaio. A Ciência do direito. 2. ed. São Paulo: Atlas, 1980.

FIANI, Ronaldo. Teoria dos Jogos: com aplicações em economia, administração e ciências sociais. 3. ed. Rio de Janeiro: Campus, 2009.

HART, Herbert Lionel Adolphus. O Conceito de direito. Tradução de A. Ribeiro Mendes, a partir da $2^{\mathrm{a}}$ edição do The Concept of Law, 1994. 3. ed. Lisboa: Fundação Calouste Gulbenkian, 2001.

HARVARD LAW SCHOOL LIBRARY. Verbete no Digital Suite. Disponível em: <http://library.law.harvard.edu/suites/owh/>. Acesso em: 25 ago. 2017.

HOLMES JUNIOR, Oliver Wendell. The Path of Law. Harvard Law Review, v. 10, n. 8, p. 457-478, mar/1897.

HOLMES JUNIOR, Oliver Wendell. The Common Law. (Revisão gráfica por Paulo J. S. Pereira e Diego M. Beltran, a partir da edição de 1881). Toronto, University of Toronto Law School, 2011.

KELSEN, Hans. Teoria Pura do direito. Tradução de João Baptista Machado. 6. ed. São Paulo: Martins Fontes, 1998.

KUHN, Thomas S. A Estrutura das Revoluções Científicas. 5. ed. São Paulo: Perspectiva, 1998.

LARENZ, Karl. Metodologia da Ciência do direito. Tradução de José Lamego. 3. ed. Lisboa: Carlouste Gulbenkian, 1997.

LOSANO, Mario G. Os Grandes Sistemas Jurídicos. São Paulo: Martins Fontes, 2007.

MACCORMICK, Neil. Retórica e o Estado de direito. Rio de Janeiro: Elsevier, 2008.

MEZZAROBA, Orides; SERVILHA, Cláudia Monteiro. Manual de metodologia da pesquisa 
do direito. 8. ed. São Paulo: Saraiva Educacional, 2019.

OBAMA II, Barack Hussein. [Discurso proferido por ocasião da captura e assassinato de Osama Bin Laden em $1^{\circ}$ de maio de 2011]. Disponível em:

https://www.youtube.com/watch?v=opYJ3XWc37E Acesso em 13 jul. 2021.

PEIRCE, Charles Sanders. Semiótica. 3. ed. São Paulo: Perspectiva, 2005.

PERELMAN, Chaïm; OLBRECHTS-TYTECA, Lucie. Tratado da Argumentação: a nova retórica. São Paulo: Marins Fontes, 2005.

POSNER, Richard A. Economic Analysis of Law. 8. ed. New York: Wolters Kluwer, 2011.

POSNER, Richard A. The Crisis of Capitalist Democracy. Cambridge/London: Harvard, 2010a.

POSNER, Richard A. A Economia da Justiça. São Paulo: WMF Martins Fontes, 2010b.

POSNER, Richard A. Problemas de Filosofia do direito. São Paulo: Martins Fontes, 2007.

RABBAN, David M. The Historiography of The Common Law. Law \& Social Inquiry, v. 28, n. 4, p. 1161-1201 (2003). Disponível em:

https://www.jstor.org/stable/1215802?seq=2\#page_scan_tab_contents Acesso em: 13 jul. 2021.

RAZ, Joseph. O Conceito de Sistema Jurídico: uma introdução à teoria dos sistemas jurídicos. São Paulo: WMF Marins Fontes, 2012.

REALE, Miguel. Filosofia do direito. 18. ed. São Paulo: Saraiva, 1998.

ROSS, Alf Niels Christian. Direito e Justiça. Bauru, SP: EDIPRO, 2000.

STRECK, Lenio Luiz. Verdade e Consenso: constituição, hermenêutica e teorias discursivas. 4. ed. São Paulo: Saraiva, 2012. 